\title{
Investigation of Multi-layered Fire Doors with Gypsum Layer Exposed to Fire
}

\author{
Remigijus Guobys ${ }^{1}$, Vadim Mokshin ${ }^{1 *}$ \\ ${ }^{1}$ Department of Mechanical and Materials Engineering, Faculty of Mechanics, Vilnius Gediminas Technical University, J. Basanavičiaus \\ str. 28, 03224 Vilnius, Lithuania \\ * Corresponding author, e-mail: vadim.moksin@vilniustech.It
}

Received: 02 February 2020, Accepted: 09 April 2021, Published online: 21 April 2021

\begin{abstract}
This article analyzes gypsum board dehydration effect on heat conductivity and deformation of multi-layered mechanical structures subjected to temperature changes. Specially designed structures (fire doors) consisting of steel sheets with stone wool and gypsum insulating layers in between were heated in furnace for a specified period of time of not less than 60 min. Temperature versus time curves and deformations of multi-layered structures were obtained. Experimental results were verified by numerical simulation. Experimental data was found to be in good agreement with numerical simulation results. The percent differences between door temperatures from simulation and fire test don't exceed $9 \%$. This shows that thermal behavior of such multi-layered structures can be investigated numerically avoiding time-consuming and expensive fire tests. The data obtained allowed to calculate convective heat transfer coefficient of gypsum board, which was fitted into multi-layered mechanical structure. It was found that it is more advantageous to place gypsum layer in the middle of the structure rather than closer to the fire source in order to cool the structure more efficiently during fire.
\end{abstract}

\section{Keywords}

deformation, dehydration, fire test, gypsum, multi-layered structure, numerical simulation, temperature

\section{Introduction}

Fire safety of a building system plays a vital role from preventing the building collapse to protecting building occupants if fire exposure was to occur [1].

Modern constructions and large products are often produced of prefabricated multi-layered mechanical structures, which exhibit high specific stiffness, strength, environmental resistance and thermal insulation characteristics [2, 3]. Such mechanical structures are widely used in residential and industrial buildings [4, 5], thermal and nuclear power stations, space stations, ships [6-8] and airplanes [9]. They can be used as fixed partitions or mobile constructions. However, poor fire resistance is the critical problem of multi-layered structures in engineering applications $[2,5,9]$. Most of the materials used in such structures are flammable [2]. In the presence of fire, the structures decompose, ignite, and burn releasing heat, smoke, and toxic gases [2]. The released heat and toxic gases from the polymers can cause serious injury and death [2]. Moreover, the load-bearing capacity of multi-layered structures is significantly reduced, and the structure is weakened by the damage from the fire, leading to failure $[2,10]$. To use in structural applications, the fire resistance of multi-layered structures should be improved [2]. The fire performance of such structures has been a topic of investigation in recent years [5].

Heat reduction can be achieved by using polymer [2, 5] and liquid fillers [11], however, such method of cooling is too complicated and expensive to use in most applications.

Wood structures are good thermal insulators; however, their insulation time is limited by high burning rate of wood, which is about $2 \mathrm{~mm} / \mathrm{min}$ [12].

Gypsum is a natural, cheap, and ecologic raw material, which provides excellent fire protection because it dehydrates at a temperature around $100^{\circ} \mathrm{C}$ absorbing energy and acting as a heat barrier [3]. However, the dehydration process severely deteriorates its integrity causing the material to lose most of the ambient temperature strength [1, 13]. The use of thin steel sheathing can provide enhanced stiffness to structures while also improving strength, impact resistance, blast resistance, mechanical or seismic vibration resistance and durability [1]. 
In this study, experimental and numerical investigations of fire resistance properties of two multi-layered mechanical structures (fire doors) were carried out in accordance with the requirements presented in $[14,15]$. These investigations comprise simulation and measurements of temperatures and deformations at certain points of real-scale structure subjected to thermal load. The influence of constituents of such structures on their thermal conductivity and temperature deformations was analyzed.

This study analyses materials having ability to cool the constructions heated in fire for some period of time. We used gypsum boards for steel cooling in this study.

\section{Test equipment and technique}

Multi-layered structure (fire door) to be analyzed has dimensions of $2090 \times 980 \times 62 \mathrm{~mm}$ and consists of an outer steel sheet of $1 \mathrm{~mm}$ thickness, a gypsum board (density $840 \mathrm{~kg} / \mathrm{m}^{3}$ ) of $10 \mathrm{~mm}$ thickness and a stone wool (density $140 \mathrm{~kg} / \mathrm{m}^{3}$ ) plate of $50 \mathrm{~mm}$ thickness covered on the inside with a steel sheet of $1 \mathrm{~mm}$ thickness (Fig. 1). The whole door structure consists of two parts (door and frame) interconnected by hinged joints - two hinges and a lock latch. Structure was investigated numerically using SolidWorks Simulation software. Transient thermal analysis was performed. Governing equations of heat transfer and their numerical approximations are presented in [16]. The following initial conditions were used for temperature and thermal deformations calculations: $X=0$ and $X=L_{X}$, $Y=0$ and $Y=L_{Y}$, duration of temperature exposure was $3600 \mathrm{~s}$, initial temperature was $15^{\circ} \mathrm{C}$. Temperature was increased according to ISO 834 standard [17] fire curve. Temperatures were calculated at 600-second time intervals. The layers forming the model were in contact with each other in certain points. It was assumed that layers of the model were combined into a single body through these contact points. It was simulated using an iterative solver FFEPlus, which solves faster and is recommended for models with many degrees of freedom. It uses the approximate techniques to solve the tasks and calculates the associated errors. Iterations continue until errors become acceptable. The properties of materials were considered temperature dependent, and their values were taken from the corresponding graphs [16].

The model presented in Fig. 1 was meshed into 3D solid first-order finite elements. They were chosen in three sizes to obtain minimum number of finite elements, thus avoiding large errors. Coarser bodies were meshed into larger-sized finite elements. The largest bodies (stone wool and gypsum layers) were meshed into elements of $44.5015 \mathrm{~mm}$ size and hinged joints (hinges and lock latch) were meshed into elements of $4.34324 \mathrm{~mm}$. Size of elements of metal construction was $20.5545 \mathrm{~mm}$. The total number of finite elements of the whole model was 245554 , the number of degrees of freedom - 7204, the number of nodes - 54143 . Results of numerical simulation of temperature changes were used as one of the boundary conditions for simulation of thermal deformations. A coefficient of friction of 0.05 was selected. The door frame was rigidly fixed at eight points (four are shown in Fig. 1 by green arrows).

Because of asymmetry of investigated structure, two cases were analyzed. In the first case (door A), gypsum layer was on the opposite side of the heat source. In the second case (door B), the gypsum layer was on the heat source side. A pressure of $20 \mathrm{~Pa}$ was applied on the heating side. Such boundary conditions were fully consistent with the method of fastening the doors used in the real fire tests and forces acting on the experimental model.

Multi-layered structure was also investigated experimentally in fire test. Two fire doors (A and B) were installed into a brick wall (200 mm thick). The wall with installed specimens was then hermetically fastened to the furnace. The temperature inside the furnace was controlled using six thermocouples distributed evenly inside the furnace. Thermocouple signals were transmitted to computer, which compares measured and programmed temperature values and controls fuel valve of the furnace. Initial temperature inside the furnace at beginning of the fire test was equal to $15^{\circ} \mathrm{C}$. Then it was increased according to ISO 834 standard fire curve. Pressure inside the furnace was kept constant $(20 \mathrm{~Pa})$ throughout the whole fire test. The fire test was terminated after $60 \mathrm{~min}$.

Door temperature outside the furnace during fire test was measured by thermo elements attached to the door at measuring points (Fig. 2). Thermal deformations of the

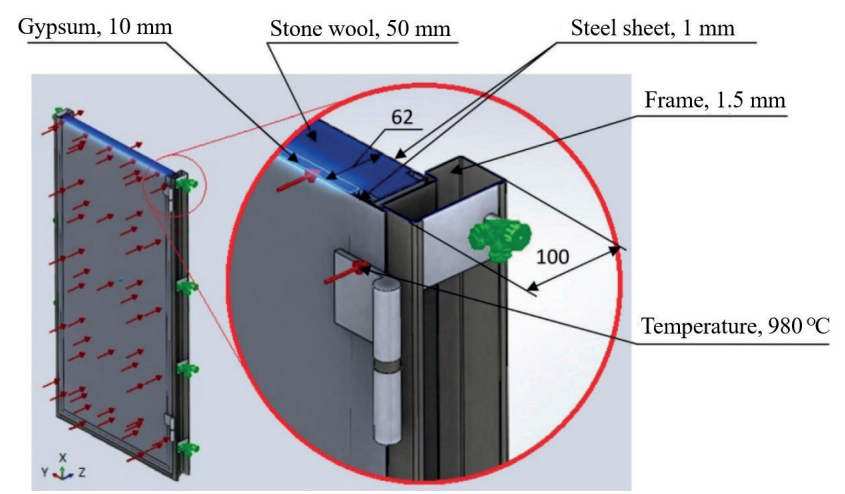

Fig. 1 3D model of multi-layered structure 


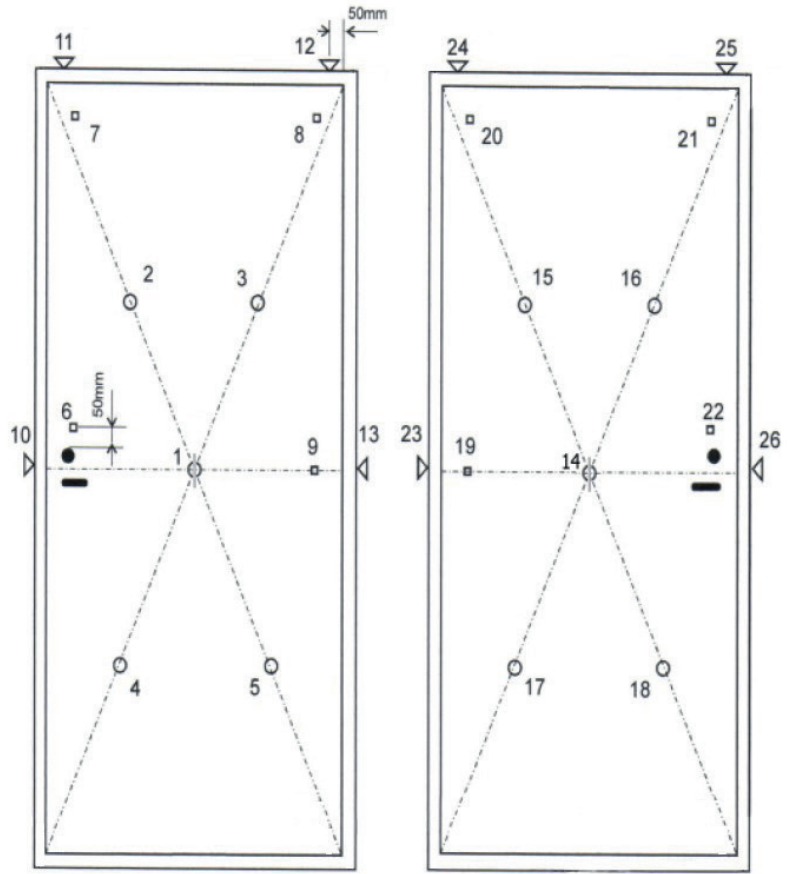

Fig. 2 Temperature measuring points of the door A (left) and B (right)

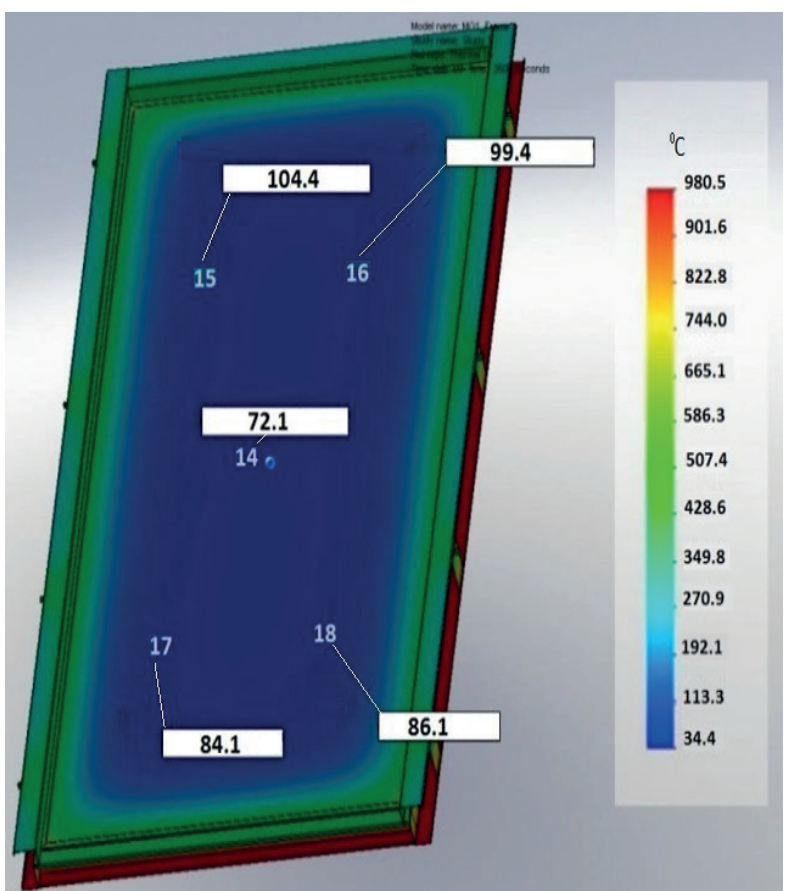

Fig. 3 Temperature distribution in door B after fire test

Points (Fig. 2):

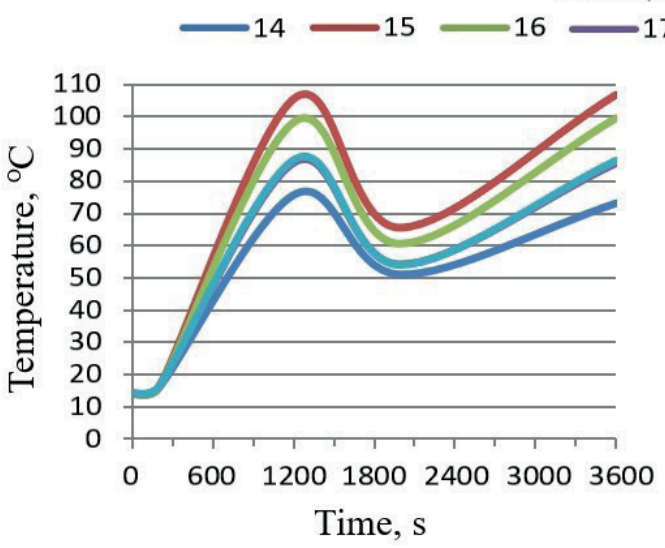

(a)

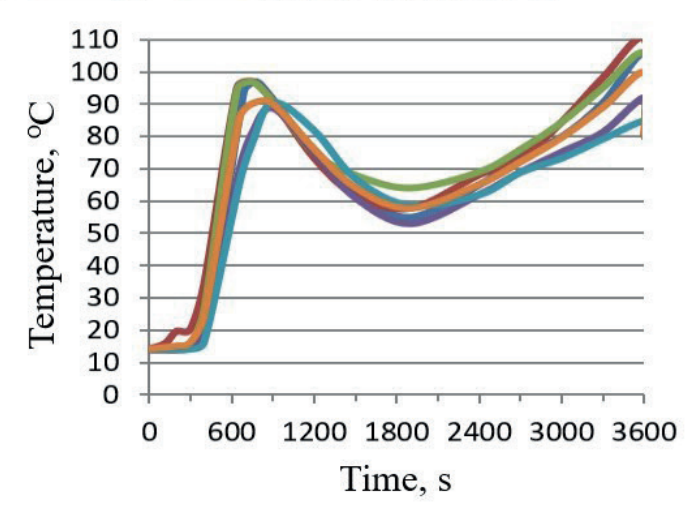

(b)

Fig. 4 Temperature versus time curves of the door B: a) - obtained in numerical simulation; b) - obtained in fire test

structure were measured with respect to the wall at measuring points. For that purpose, three horizontal steel strings were attached to the wall before investigated structure. Thermal deformations of the structure were measured with respect to these strings by means of caliper.

\section{Results and discussion}

After simulation, temperature values at the points 14-18 (Fig. 3) corresponding to the points where the temperature was measured during the experiment were distinguished. Temperature change curves obtained in computer simulation and fire test of the door B are shown in Fig. 4.

It can be seen from Fig. 4(b) that temperature of steel sheet of the door B measured at points 14, 15, 16, 17, 18
(Fig. 2) immediately began to rise and after 15 minutes reached $90-98^{\circ} \mathrm{C}$, then it began to drop suddenly to 55-65 ${ }^{\circ} \mathrm{C}$ (Fig. 4(b)). Temperature changes obtained in simulation were similar (Fig. 4(a)). Due to the composition of layers, this multi-layered structure cooled itself for about 20 minutes. Subsequently, the temperature rose steadily at a rate of about $1.5^{\circ} \mathrm{C} / \mathrm{min}$. Such "self-cooling" effect was observed throughout the structure, wherever there was contact with the gypsum.

Temperature change curves obtained for other measuring points of the door B are presented in Fig. 5. It can be seen from Fig. 5 that the temperature measured at measuring points $19,20,21,22$ decreased less $\left(10-20^{\circ} \mathrm{C}\right.$ only) as compared with points $14-18$ (Fig. 4) as points 19-22 
(Fig. 2) are located closer to the edges and were more intensively heated by the steel edges than points located closer to the center of the structure.

Temperature change curves obtained in fire test of the door A are shown in Fig. 6. As can be seen from Fig. 6, the "self-cooling" effect noticed for structure B is not observed for A case.

Thermal deformations of structures $\mathrm{A}$ and $\mathrm{B}$ were determined by numerical simulation and experimentally. The central area of structure A remained almost unchanged, but the edges that are most distant from the interconnection of the segments were protruded away from the heat source (Fig. 7(a)). Deformations obtained in numerical simulation and fire test were similar and reached about $22 \mathrm{~mm}$ at maximum.

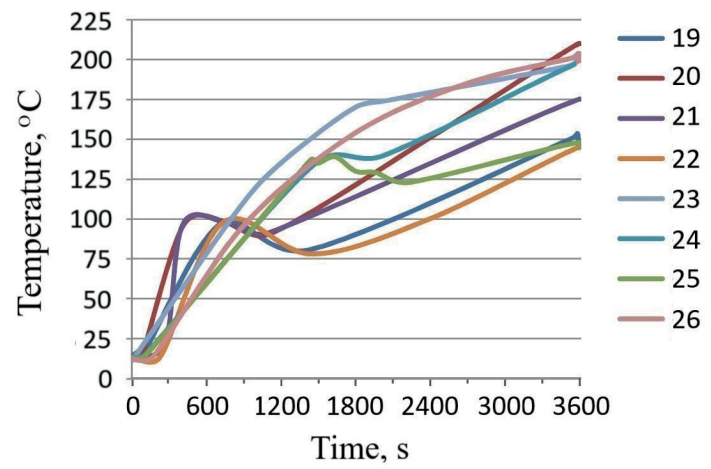

Fig. 5 Temperature versus time curves of the door B obtained for points 19-26 (Fig. 2) in fire test
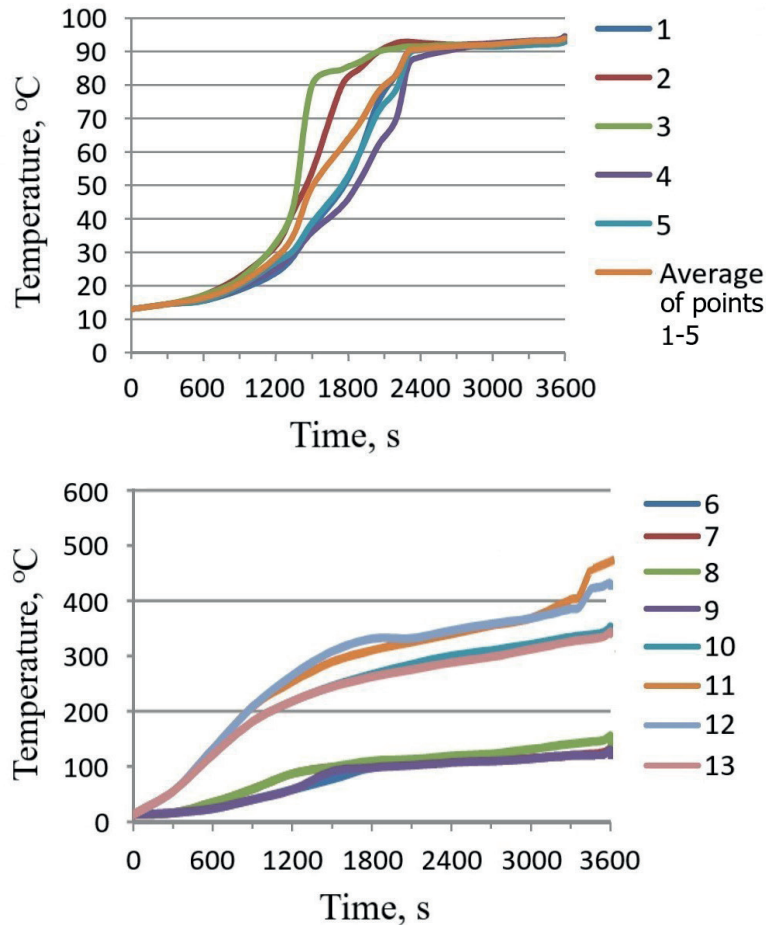

Fig. 6 Temperature versus time curves obtained in fire test of the door A (1-13 - measuring points (Fig. 2))
Deformations in the central area of the structure B were greatest (Fig. 7(b)) compared to the structure A (Fig. 7(a)). Numerical simulation results show that the structure B curved up to $25 \mathrm{~mm}$ towards the heat source (Fig. 7(b)). It was established after the real fire test that the central area of the structure B was deformed $27 \mathrm{~mm}$ towards the heat source.

The results obtained (Fig. 3) show that the frame was heated more than the door because there was no gypsum inside, only a layer of stone wool. The temperature at

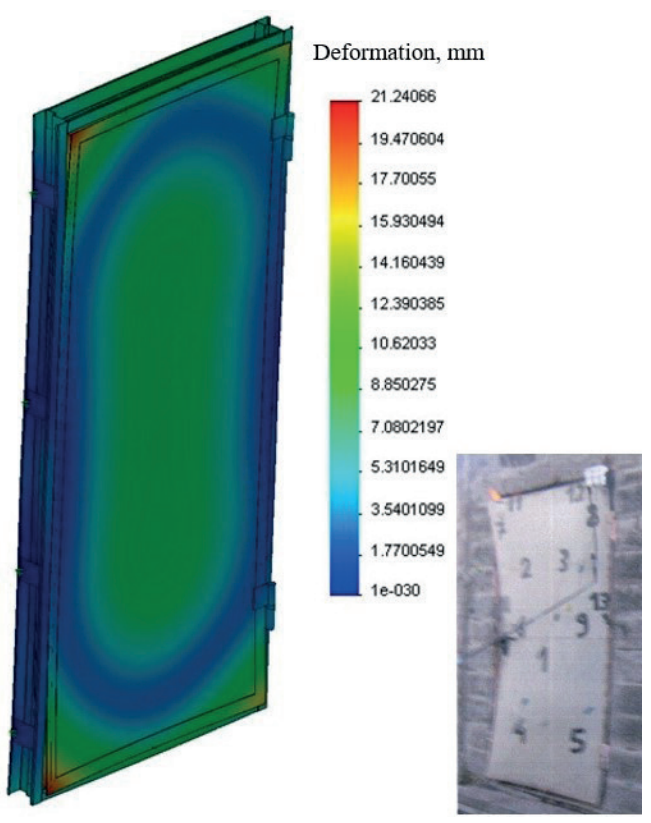

(a)
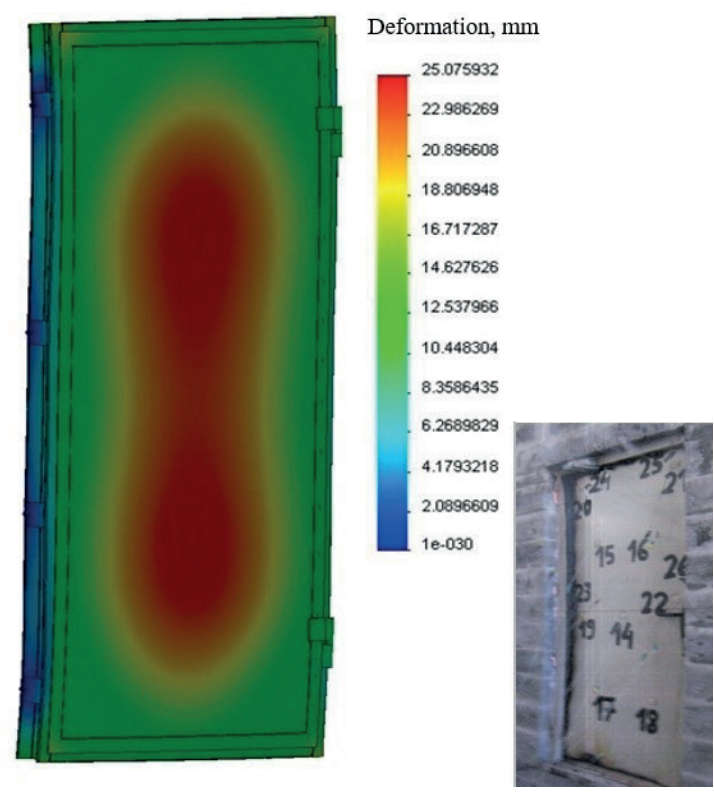

(b)

Fig. 7 Thermal deformations of multi-layered structure after $60 \mathrm{~min}$ fire exposure obtained from numerical simulation (door photos after fire tests are shown in the bottom right): a) - model A; b) - model B 
the edges of the door shown in Fig. 3 ranges from 280 to $360^{\circ} \mathrm{C}$ and frame temperature reaches $600^{\circ} \mathrm{C}$. Such temperatures are dangerous to the premises as they can cause fire and burn evacuees.

Based on the simulation results, the design of the multi-layered structure was modified by placing two $10 \mathrm{~mm}$ thick gypsum layers on either side of the central steel sheet. A cross section of multi-layered structure with three steel layers is shown in Fig. 8. The main middle sheet providing the strength to the structure consists of $0.8 \mathrm{~mm}$ thick steel sheet with welded edges connecting the exterior steel layers. The reinforcing steel exterior layers are made of thicker ( $3 \mathrm{~mm}$ thick) steel, but they do not completely cover the entire area of the structure. The outer sides of the structure are covered by $12 \mathrm{~mm}$ thick chipboard plates. The remaining steel structure cavities were filled with stone wool of $140 \mathrm{~kg} / \mathrm{m}^{3}$ density.

Temperature change curves obtained in fire test are presented in Fig. 9.

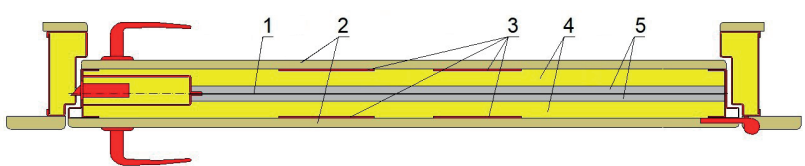

Fig. 8 Cross-section of modified multi-layered structure: 1 - steel sheet; 2 - chipboard plate; 3 - steel profile; 4 - stone wool insulation layer; 5 - gypsum layer

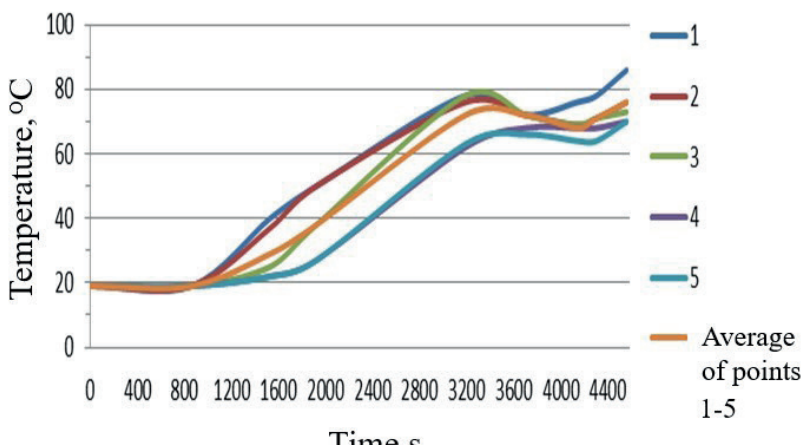

Time,s

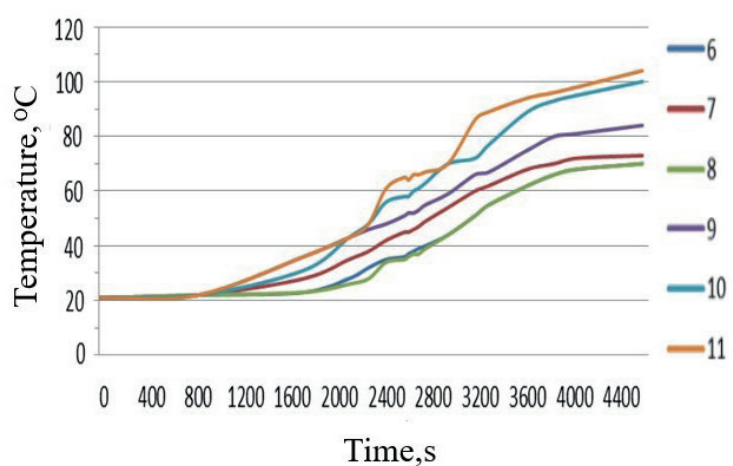

Fig. 9 Temperature versus time curves obtained in fire test of the door shown in Fig. 8 (1-11 - measuring points (Fig. 2))
It can be seen from Fig. 9 that temperature values of modified design door after 1 hour and 15 minutes reached $102^{\circ} \mathrm{C}$, with thermal deformation values ranging from 1.5 to $5 \mathrm{~mm}$ in the central part of structure (Fig. 10).

The location of insulating gypsum layers in the structure has significant influence on the temperature propagation over time. Results have shown that structure with gypsum layer located closer to the heat source (Fig. 4) cools itself more efficiently, but in a shorter period of time as compared with structure with gypsum layers located in the middle (Fig. 9, Fig. 11).

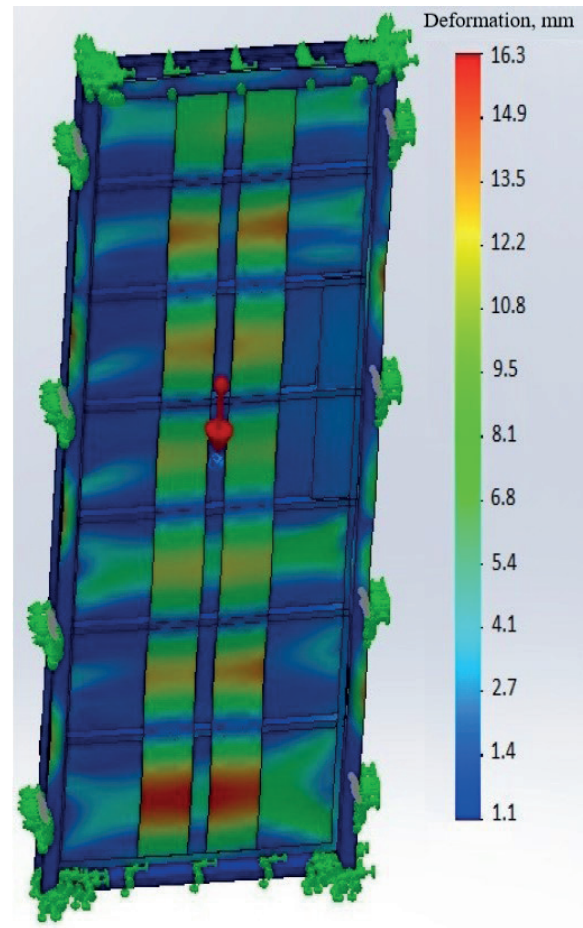

Fig. 10 Thermal deformations of modified multi-layered structure after $75 \mathrm{~min}$ fire exposure (numerical simulation results)

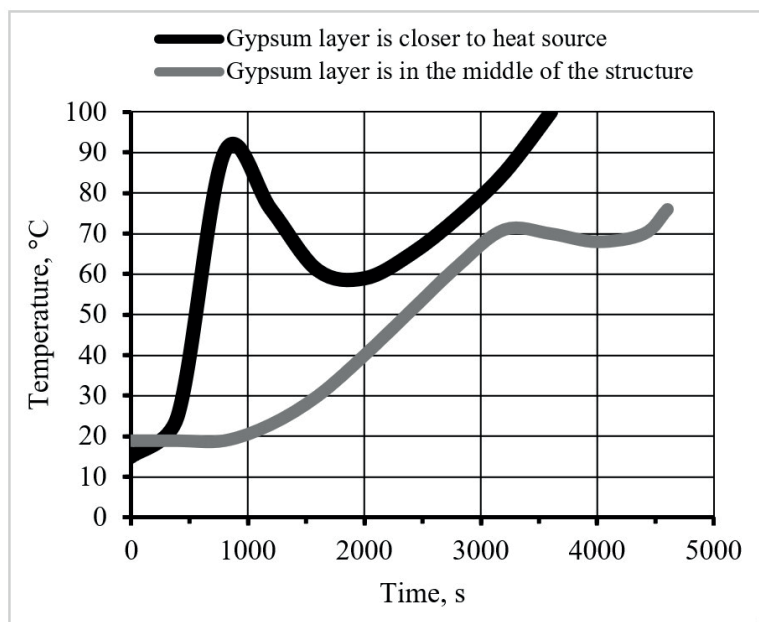

Fig. 11 Comparative temperature versus time curves 


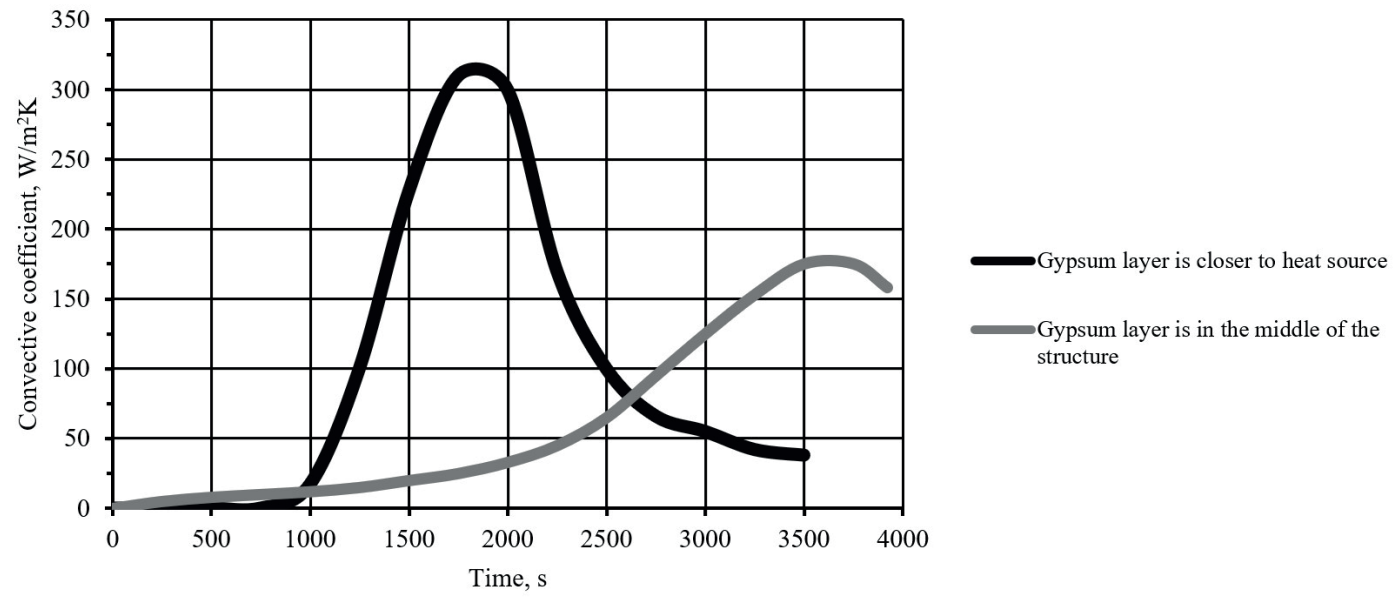

Fig. 12 Convective heat transfer coefficient of insulating layer versus time graphs

Experiments have shown that the sudden rise in temperature destroys gypsum insulating layer, it immediately turns to powder and falls to the bottom of the structure. Therefore, the structure with gypsum insulating layer located closer to heat source cannot maintain uniform cooling throughout the whole area of the structure.

The best results in terms of fire safety of investigated structures were obtained with a multi-layered structure with gypsum cooling layers (Fig. 11) in the middle. Maximum gypsum convection was observed nearly an hour after the test started and lasted about 20 minutes before the wood trim ignited. According to the test results, about $70 \%$ the gypsum was not disintegrated and would have cooled the structure further if finishing materials had higher fire resistance. Based on the average temperature change curves obtained during the fire tests (Fig. 11), the values of the convective heat transfer coefficient of the gypsum layer were determined. These curves are presented in Fig. 12.

\section{References}

[1] Steau, E., Mahendran, M., Poologanathan, K. "Experimental study of fire resistant board configurations under standard fire conditions", Fire Safety Journal, 116, Article No. 103153, 2020. https://doi.org/10.1016/j.firesaf.2020.103153

[2] Kim, M., Choe, J., Lee, D. G. "Development of the fire-retardant sandwich structure using an aramid/glass hybrid composite and a phenolic foam-filled honeycomb", Composite Structures, 158, pp. 227-234, 2016.

https://doi.org/10.1016/j.compstruct.2016.09.029

[3] Soloveiko, S., Pulkis, K., Skujans, J., Aboltins, A. "Composite sandwich-type panel made of foamgypsum", In: Proceedings of 17th International Scientific Conference on Engineering for Rural Development, Jelgava, Latvia, May, 23-25, 2018, pp. 1482-1487. https://doi.org/10.22616/ERDev2018.17.N347

\section{Conclusions}

Numerical simulation and experimental results have shown that the use of gypsum layer in multi-layered structure significantly improves its performance in fire, which depends on layer location in the structure.

Deformations between individual segments of multilayered structure are limited by rigid or flexible joints, and the influence of temperature on the structure is reduced by use of appropriate materials (i.e., gypsum) with good self-cooling abilities. Despite the furnace was heated to $980^{\circ} \mathrm{C}$, gypsum reduced the temperature of the center area of the structure up to $70-80{ }^{\circ} \mathrm{C}$.

The disintegration mechanisms of gypsum layers depending on their location in multi-layered structure were determined. Gypsum layer placed near heat source is completely destroyed while when located in the middle of the structure, up to $70 \%$ of gypsum layer remain undestroyed after the fire test.

The difference between simulation and experimental results is about $9 \%$.

[4] Cooke, G. M. E. "Resisting Collapse of Steel-faced Sandwich Panel Walls and Ceilings Exposed to Fire", Journal of Fire Protection Engineering, 18(4), pp. 275-290, 2008.

https://doi.org/10.1177/1042391508087839

[5] Pereira, D., Cago, A., Proença, J., Morgado, T. "Fire performance of sandwich wall assemblies", Composites Part B: Engineering, 93, pp. 123-131, 2016. https://doi.org/10.1016/j.compositesb.2016.03.001

[6] Marquis, D. M., Pavageau, M., Guillaume, E. "Multi-scale simulations of fire growth on a sandwich composite structure", Journal of Fire Sciences, 31(1), pp. 3-34, 2013. https://doi.org/10.1177/0734904112453010 
[7] Lua, J. "Hybrid Progressive Damage Prediction Model for Loaded Marine Sandwich Composite Structures Subjected to a Fire", Fire Technology, 47(4), pp. 851-885, 2011. https://doi.org/10.1007/s10694-009-0124-6

[8] Legrand, V., TranVan, L., Casari, P., Jacquemin, F. "Structureproperties relationships of moisturized sandwich composite materials under extreme temperature conditions (fire resistance)", Composite Structures, 235, Article No. 111774, 2020. https://doi.org/10.1016/j.compstruct.2019.111774

[9] Rizk, G., Legrand, V., Khalil, K., Casari, P., Jacquemin, F. "Durability of sandwich composites under extreme conditions: Towards the prediction of fire resistance properties based on thermo-mechanical measurements", Composite Structures, 186, pp. 233-245, 2018. https://doi.org/10.1016/j.compstruct.2017.12.009

[10] Dao, M., Asaro, R. J. "A study on failure prediction and design criteria for fiber composites under fire degradation", Composites Part A: Applied Science and Manufacturing, 30(2), pp. 123-131, 1999. https://doi.org/10.1016/S1359-835X(98)00051-7

[11] Keller, T., Zhou, A., Tracy, C., Hugi, E., Schnewlin, P. "Experimental study on the concept of liquid cooling for improving fire resistance of FRP structures for construction", Composites Part A: Applied Science and Manufacturing, 36(11), pp. 1569-1580, 2005.

https://doi.org/10.1016/j.compositesa.2004.10.032
[12] Joyeux, D. "Experimental investigation of fire door behaviour during a natural fire", Fire Safety Journal, 37(6), pp. 605-614, 2002. https://doi.org/10.1016/S0379-7112(02)00003-6

[13] Yoshitani, K., Shimizu, T., Yoshida, M. "Study on prediction method for the insulation of gypsum board using inclusive thermal conductivity in fire resistance tests", Japan Architectural Review, 1(4), pp. 548-562, 2018. https://doi.org/10.1002/2475-8876.12057

[14] CEN "EN 1363-1: Fire resistance tests: General requirements", European Committee for Standardization, Brussels, Belgium, 2000.

[15] CEN "EN 1634-1: Fire resistance tests for door and shutter assemblies - Part 1: Fire doors and shutters", European Committee for Standardization, Brussels, Belgium, 2000.

[16] Guobys, R. "Investigation of multilayer structures in fire", $\mathrm{PhD}$ Thesis, Vilnius Gediminas Technical University, 2014.

[17] ISO "ISO 834-1:1999 Fire-resistance tests - Elements of building construction", International Organization for Standardization, Geneva, Switzerland, 1999. 